\title{
EFTEM Study of Phase Separations in Borosilicate Glasses Under Electron Beam Irradiation
}

\author{
K. Sun, L. M. Wang and R. C. Ewing \\ Department of Nuclear Engineering and Radiological Sciences, University of Michigan, Ann Arbor, \\ MI 48109
}

Phase-separation in glasses used for nuclear waste vitrification can results in degradation of the chemical durability of the glasses. Thus, the subject has been studied extensively using various techniques, such as electron microscopy [1], nuclear magnetic resonance [2], and electron energyloss spectroscopy (EELS) etc [3]. Borosilicate glass that has been chosen as a waste form for most nuclear waste compositions in most countries that have high-level radioactive wastes is among the most widely studied glasses [4]. Phase separation in glasses under irradiation is always a concern [4]. So far, little is known about the effects of cations with multiple valence states, like Fe on the phase separation. Direct evidences showing element redistribution after the phase separation are needed.

In the present study, we performed in-situ electron energy-loss spectroscopy (EELS) and energyfiltered electron microscopy (EFTEM) studies (using a JEOL-2010F STEM/TEM performed in TEM mode) on three alkali borosilicate glasses. The samples were named as NBS-1 $\left(17.72 \% \mathrm{~B}_{2} \mathrm{O}_{3}\right.$ $\left.16.67 \% \mathrm{Na}_{2} \mathrm{O}-64.61 \% \mathrm{SiO}_{2}\right)$, NBS-2 (17.78\% $\left.\mathrm{B}_{2} \mathrm{O}_{3}-15.83 \% \mathrm{Na}_{2} \mathrm{O}-61.39 \% \mathrm{SiO}_{2}-4.99 \% \mathrm{Fe}_{2} \mathrm{O}_{3}\right)$ and NBS-3 (17.86\% $\left.\mathrm{B}_{2} \mathrm{O}_{3}-15.90 \% \mathrm{Na}_{2} \mathrm{O}-61.63 \% \mathrm{SiO}_{2}-4.61 \% \mathrm{FeO}\right)$. Results indicate that all the glasses started to lose their mass under the electron irradiation that can be seen from the thinning of the glasses during the irradiation. Na migration to the nearby regions has also been noticed during irradiation. No $\mathrm{Na}$ can be detected by EELS from the irradiated areas after higher doses, i.e., electron irradiation has created Na-depleted areas in the irradiated glass.

With the increase of electron doses, all the three glasses showed a second phase separation phenomenon, i.e., the separation of borate phase from silica-rich phase. Figure 1 (a), (b) and (c) are $\mathrm{B}, \mathrm{Si}$ and $\mathrm{O}$ elemental maps obtained from the NBS-1 sample after irradiation by electron beam at a dose of $4.8 \times 10^{26} \mathrm{e} / \mathrm{m}^{2}$, the maps clearly show that phase separation has occurred. The generated RGB map of the three elements is shown in Figure 1d. Figure 2 (a), (b) and (c) are series RGB maps generated from B-, Si- and Fe- maps obtained from the NBS-2 sample after being irradiated with electron doses of about $2.0 \times 10^{26} \mathrm{e} / \mathrm{m}^{2}, 3.0 \times 10^{26} \mathrm{e} / \mathrm{m}^{2}$, and $5.0 \times 10^{26} \mathrm{e} / \mathrm{m}^{2}$, respectively. The series of maps clearly demonstrates the process of phase separation under irradiation. Figure $2 \mathrm{~d}$ is a HREM image showing the formation of small crystalline particles (the interplanar distance of the particle is $\sim 0.26 \mathrm{~nm}$ ) after the glass has been irradiated at a high electron dose. Figure 3 (a), (b) and (c) are B, Si and Fe elemental maps obtained from the NBS-3 sample after it have been irradiated under the electron beam at a dose of $4.8 \times 10^{26} \mathrm{e} / \mathrm{m}^{2}$; (d) is a RGB map generated from (a), (b) and (c) indicating silicate-rich and iron borate-rich phases have been generated, respectively; (e) and (f) are HAADF and BF images showing the formation of small crystals (with a small lattice). It is obvious that after the phase separation has occurred, Fe is associated with borate in both the Fe containing glasses, while the irradiation-induced nanocrystals in the two samples are different in both lattice parameters and particle sizes after a nearly same dose. This may be attributed to the possibility of different valence states and behavior of Fe atoms in the glasses. Further study is on going. 


\section{References}

[1] P.B. Adams and D.L. Evans, Mater. Res. Sci. 12 (1978) 525.

[2] W.F. Du, et al., J. Solid State Chem.149 (2000) 459.

[3] H.J. Kleebe, et al., J. Am. Ceram. Soc. 84 (2001) 1073.

[4] W.J. Weber, et al., J. Mater. Res. 12 (1997) 1946.

[5] The JEOL-2010F STEM/TEM used in this study was funded by NSF through the Grant DMR9871177 and is operated by the EMAL at University of Michigan.
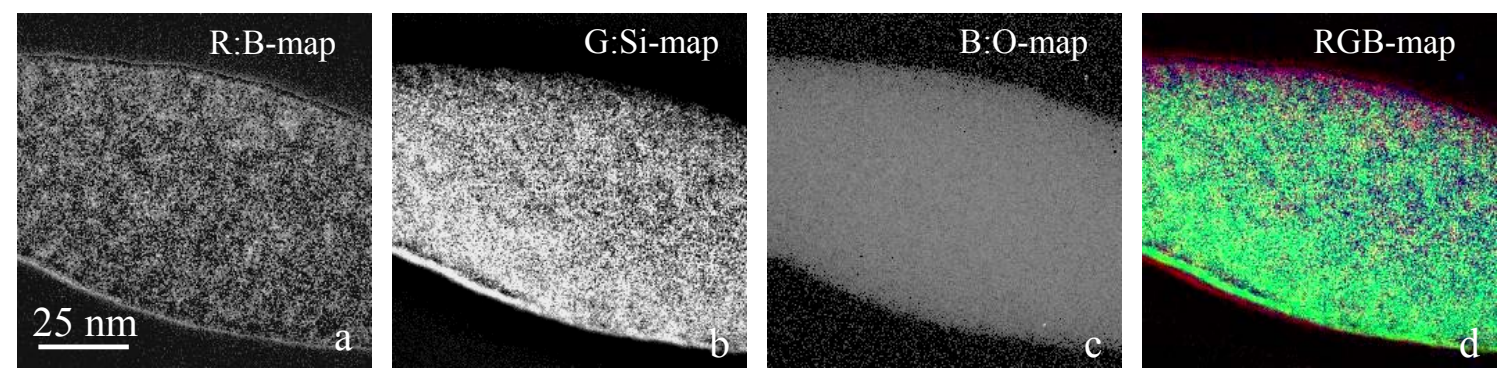

FIG. 1. (a), (b) and (c) are B, Si and O maps obtained from the NBS-1 sample after having been irradiated at a dose of $4.8 \times 10^{26} \mathrm{e} / \mathrm{m}^{2}$; (d) is a RGB map generated from (a), (b) and (c).
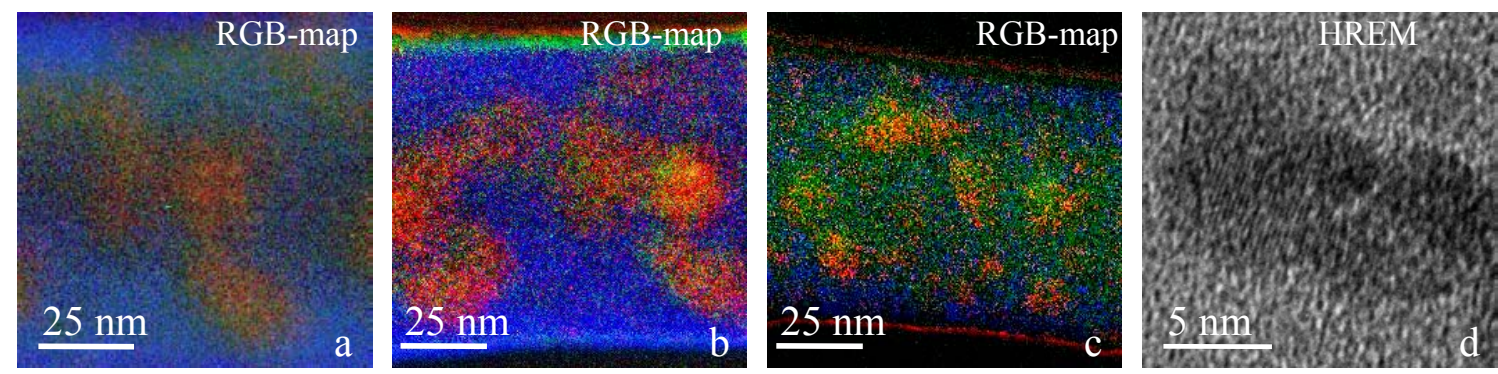

FIG. 2. RGB maps (R: B, G: Fe, and B: Si) obtained from the NBS-2 glass after it has been irradiated at doses of about (a) $2.0 \times 10^{26} \mathrm{e} / \mathrm{m}^{2}$, (b) $3.0 \times 10^{26} \mathrm{e} / \mathrm{m}^{2}$, and (c) $5.0 \times 10^{26} \mathrm{e} / \mathrm{m}^{2}$; (d) is a HREM image showing the formation of small crystalline particles.
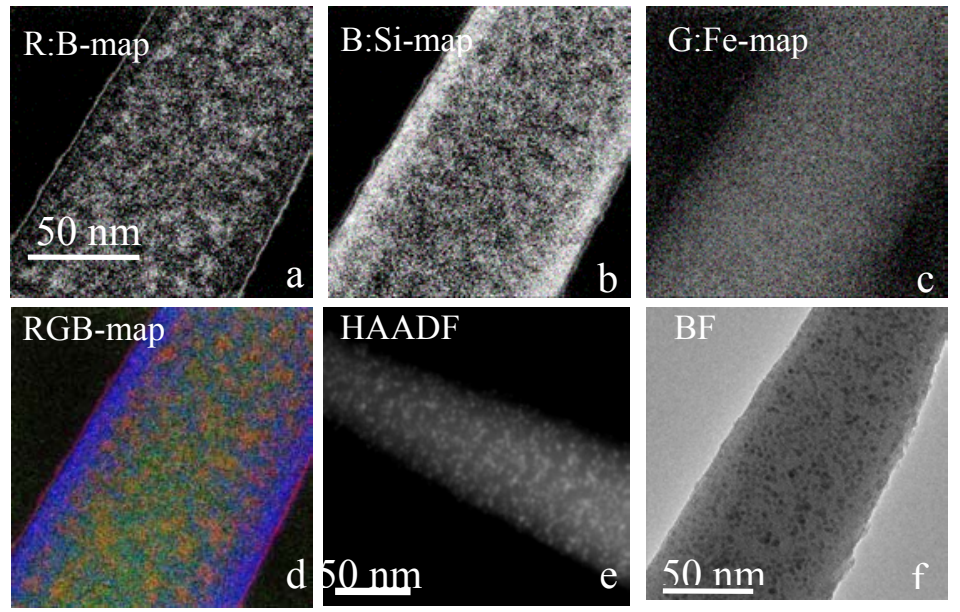

FIG. 3. (a), (b) and (c) are B, Si and Fe elemental maps obtained from the NBS-3 sample after having been irradiated at a dose of $4.8 \times 10^{26} \mathrm{e} / \mathrm{m}^{2}$; (d) is a RGB map generated from (a), (b) and (c); (e) and (f) are HAADF and BF images showing the formation of small crystals. 